\title{
Synthesis, Characterization and Thermal Properties of Silsesquioxane Organically Modified With 4,5-Diphenyl-2-Imidazolethiol
}

\author{
Devaney R. do Carmo ${ }^{1}$, Mariana de S. Magossi ${ }^{1}$, Urquisa de O. Bicalho ${ }^{1} \&$ Daniela R. Silvestrini ${ }^{1}$ \\ ${ }^{1}$ Faculdade de Engenharia de Ilha Solteira UNESP-Universidade Estadual Paulista, Ilha Solteira, Brazil \\ Correspondence: Devaney R. do Carmo, Faculdade de Engenharia de Ilha Solteira UNESP-Universidade \\ Estadual Paulista, Departamento de Física e Química, Av. Brasil Centro, 56. CEP 15385-000, Ilha Solteira, SP, \\ Brazil. Tel: 55-18-3742-1029. E-mail: docarmo@dfq.feis.unesp.br
}

Received: December 22, 2013 Accepted: February 18, 2014 Online Published: March 10, 2014

doi:10.5539/ijc.v6n2p22

URL: http://dx.doi.org/10.5539/ijc.v6n2p22

\begin{abstract}
The present paper describes the preparation of a nanostructured silsesquioxane, the octa-(3-chloropropyl)-octasilsesquioxane (S) that was organofunctionalised with the 4,5-Diphenyl-2-imidazolethiol (DIT). The modification of silsesquioxane with DIT proposed in this paper follows two steps. The composite prepared after functionalization was ascribed as SDIT. The composite SDIT and precursors were characterized by infrared (FTIR), ${ }^{13} \mathrm{C}$ and ${ }^{29} \mathrm{Si}$ Nuclear Resonance Magnetic (NMR) in solid state, Scanning Electron microscopy (SEM); X-Ray Diffraction (XRD); Energy-Dispersive X-ray spectroscopy (EDS) and Thermogravimetry. By spectroscopic analysis using above techniques, we conclude with that the SDIT synthesis was conducted with success. It was observed a cluster of particles containing cavities in an orderly fashion. The themogravimetry analyzes performed in two different atmospheres, concluding that the materials (S, DIT and SDIT) when in air atmosphere has a slower degradation process in relation to nitrogen atmosphere. The thermogravimetry of SDIT indicate a greater thermal stability in nitrogen atmosphere.
\end{abstract}

Keywords: silsesquioxane, functionalization, 4,5-diphenyl-2-imidazolethiol

\section{Introduction}

In the economic and scientific context, various companies and universities are currently researching new materials from polyhedral oligosilsesquioxanes (POSS). Silsesquioxanes are materials with an empirical formula $\left(\mathrm{RSiO}_{1.5}\right)$ n, where $\mathrm{R}$ is a hydrogen atom or an organic group (Do Carmo, Bicalho, Silveira, Dias Filho, \& Paim, 2013; Cordes, Lickiss, \& Rataboul, 2010; Baney, Itoh, Sakakibara, \& Suzukit, 1995; Kuo \& Chang, 2011; Xu, Loo, \& Wang, 2011; Tanaka \& Chujo, 2012; Li-Chih \& Shea, 2011) and $n=4,6,8,10(n \geq 4)$ (Cordes, Lickiss, \& Rataboul, 2010). Due to their intrinsic quality properties, and as a consequence in recent years there has been a large increase in the number of patents and publications related to these materials (Laine \& Roll, 2011; Cordes, Lickiss, \& Rataboul, 2010).

Such exponential increase in the number of researchers, publications, government and industrial incentive programs has resulted in these nanomaterials representing great potential in the field of nanoscience and nanotechnology (Phillips, Haddad, \& Tomezak, 2004). The interest in this family of compounds has generated 14 review articles covering many ways on the synthesis, chemistry and properties of silsesquioxanes (Laine \& Roll, 2011; Cordes, Lickiss, \& Rataboul, 2010). However a recent literature search did not find any reports on the chemical modification of silsesquioxanes and their application to the molecules under study in this article, employing or not the proposed methodology.

In present work, we reported synthesis and characterization of a octa-(3-chloropropyl)-octasilsesquioxane (S) with 4,5-Diphenyl-2-imidazolethiol (DIT) and thermal properties of this modified silsesquioxane.

The modification of silsesquioxane with DIT proposed in this paper follows two steps. The first step includes 8 $\mathrm{Cl}$ reactive atoms of the nanoplataform octa-(3-chloropropyl)-octasilsesquioxane, whose structure is shown in Figure 1, which are replaced to the chloride ion form by stronger bases (shiff bases), in this case the DIT, favoring the nucleophilic substitution reaction. The DIT ligand was used due to the fact it has $-\mathrm{NH}$ and $-\mathrm{NH}_{2}$ groups suitable to organofunctionalization, and also -S groups which are excellent active sites for metal ions. In this context, the organomodified silsesquioxanes (SDIT) is a potentially candidate for sorption of metal ions. 

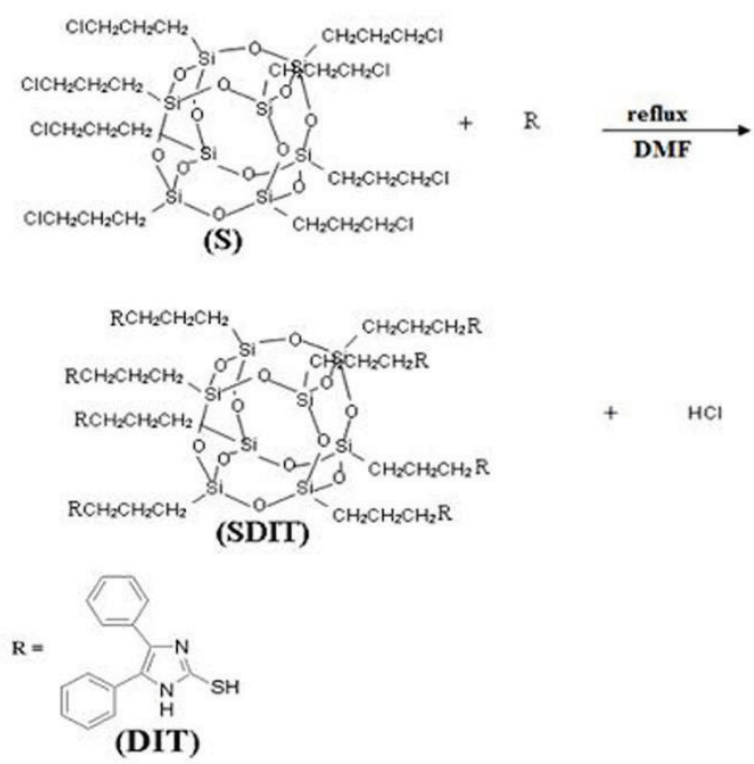

Figure 1. Organofunctionalization of octa-(3-chloropropyl)octasilsesquioxane (S) with modifier 4,5-Diphenyl-2-imidazolethiol (DIT)

\section{Material Studied}

\subsection{Reagents}

All reagents and solvents were of high purity analytical grade (Vetec, Alpha Aesar, Merck or Sigma- Aldrich) and were used as purchased. Deionized water were produced with Milli-Q Gradient system from Millipore.

\subsection{Techniques}

\subsubsection{Scanning Electronic Microscopy (SEM) and Energy-Dispersive X-Ray Spectroscopy (EDS)}

The scanning electron microscopy of the any materials were obtained using a JEOL JSM T-300 microscope. The samples were adhered over aluminum holders and covered with a thin layer $(20-30 \mathrm{~nm})$ of gold in Sputter Coater Bal-Tec SCD-050.

\subsubsection{Nuclear Magnetic Resonance Analyses (NMR)}

All solid state analyses of ${ }^{29} \mathrm{Si}(59.5 \mathrm{MHz})$ and ${ }^{13} \mathrm{C}-\mathrm{NMR}(75.4 \mathrm{MHz})$ were registred on a Varian INOVA 300 spectrometer. The samples were packed in zirconia rotors and spun at the magic angle at $4500 \mathrm{~Hz}$, a relaxation delay of 10.0 and $6.0 \mathrm{~s}$ for ${ }^{29} \mathrm{Si}$ and ${ }^{13} \mathrm{C}$ respectively. All chemical shifts are reported in parts per million ppm $(\delta)$ with reference to external tetramethylsilane (TMS).

\subsubsection{X-Ray Diffraction (XRD)}

The $\mathrm{X}$ ray diffraction patterns (XRD) spectroscopy were obtained using a Siemens D 5000 diffractometer with $\mathrm{CuK} \alpha\left(\lambda 1.5406 \AA\right.$ radiation), submitted to $40 \mathrm{kV}, 30 \mathrm{~mA}, 0.05^{\circ} \mathrm{s}^{-1}$ and exposed to radiation from 5 up to $50^{\circ}$ (20).

\subsubsection{Thermogravimetric Analysis (TG-DTA)}

The thermogravimetric analyzes of the samples were carried out using two equipments-SDT 2960 from TA Instruments and SDT Q600 from TA Instruments.

The thermogravimetric curves were obtained using approximately $6 \mathrm{mg}$ samples placed in alumina crucibles and subjected to a controlled air temperature program and nitrogen flow of $100 \mathrm{~mL} \mathrm{~min}{ }^{-1}$, with a heating rate of $10{ }^{\circ} \mathrm{C} \mathrm{min}^{-1}$. The sample analyzes were performed at the room temperature interval up to $1200{ }^{\circ} \mathrm{C}$.

\section{Methods}

\subsection{Synthesis of Octa-(3-chloropropyl)octasilsesquioxane (S)}

The synthesis of octa-(3-chloropropyl)octasilsesquioxane (S) was carried out as described in the literature with any modifications (Marciniec, Dutkiewicz, Marciejewski, \& Kubicki, 2008): $800 \mathrm{~mL}$ of dry methanol, $27.0 \mathrm{~mL}$ 
of hydrochloric acid $\left(\mathrm{HCl}_{\text {conc. }}\right)$ and $43.0 \mathrm{~mL}$ of 3-chloropropyliltriethoxysilane were added stirred at room temperature for 5 weeks. The solid phase was separated by filtration and was then oven dried at $120^{\circ} \mathrm{C}$ for 4 hours (Figure 1).

\subsection{Preparation of Octa-(3-chloropropyl)octasilsesquioxane With DIT (SD)}

The functionalization of octa-(3-chloropropyl)octasilsesquioxane (S) (Figure 1) was performed, as describe in the literature (Soares, Silveira, Silvestrini, Bicalho, \& Do Carmo, 2013): reacting $9.70 \times 10^{-3}$ mol of S, with $8.70 \times 10^{-2} \mathrm{~mol}$ of ligand (DIT) in dimethylformamide (DMF). Then the solid phase was washed in a Soxhlet with solvent for two days. The prepared material was oven vacuum dried at $100{ }^{\circ} \mathrm{C}$ for 4 hours. Figure 1 illustrates (Soares, Silveira, Silvestrini, Bicalho, \& Do Carmo, 2013) a scheme of this syntheses:

\section{Results and Discussion}

As ilustrated by Figure 1, the organofunctionalization of $\mathrm{S}$ with 4,5-Diphenyl-2-imidazolethiol (DIT), a chlorine atom $(\mathrm{Cl})$ in the structure of octa-(3-chloropropyl)octasilsesquioxane to be very reactive, is easily replaced by stronger bases, and represents a nucleophilic center susceptible to attack. Thus binding of groups 4,5-diphenyl-2-imidazoltiol (DIT) with the silsesquioxane also must occur through the nitrogen atom of position $1(\mathrm{~N}-\mathrm{H})$, which is the position most susceptible to the formation of $\mathrm{CN}$ bond. The synthesized material, describe here as SDIT presented as a light yellow solid.

The vibrational spectrum of octa-(3-chloropropyl)octasilsesquioxane (S), as illustrated in Figure 2(A), showed an absorption band at about $1082 \mathrm{~cm}^{-1}$ which is a typical band of the material, as it regards $\mathrm{Si}-\mathrm{O}-\mathrm{Si}_{(\mathrm{vSi}-\mathrm{O}-\mathrm{Si})}$ stretching which corresponds to the cage-shaped structure of S. Two other one absorption bands were observed at around $685 \mathrm{~cm}^{-1}$, attributed to deformation of the $\mathrm{Cl}_{(\delta \mathrm{C}-\mathrm{Cl})}$ bond, and the other at around $2950 \mathrm{~cm}^{-1}$ related to the axial deformation of the $\mathrm{C}-\mathrm{H}_{(\delta \mathrm{C}-\mathrm{H})}$ (Silverstein \& Welbster, 1996; Do Carmo, Paim, Dias Filho, \& Stradiotto, 2007).

Figures 2(B) and (C) illustrate the vibrational spectra of DIT and the functionalized materials (SDIT), respectively.

Figure 2(B) refers to the vibrational spectrum of the DIT ligand, and exhibits characteristic bands of this compound such as the bands ranging from 1300 to $1530 \mathrm{~cm}^{-1}$, related to the axial deformation vibrations of the imidazole ring bonds (Silverstein \& Welbster, 1996). The broad and intense band at $2970 \mathrm{~cm}^{-1}$ was assigned to the axial deformation $\mathrm{N}-\mathrm{H}_{(\delta \mathrm{N}-\mathrm{H})}$ (Barth, 2000; Coates, 2000)

In the region between 3200 and $3500 \mathrm{~cm}^{-1}$ the bands observed were attributed to the axial deformation of $\mathrm{N}-\mathrm{H}_{(\mathrm{v}}$ $\mathrm{N}-\mathrm{H})$, these bands probably overlap the bands attributed to the axial deformation of $\left.\mathrm{C}-\mathrm{H}_{(\mathrm{V}} \mathrm{C}-\mathrm{H}\right)$ ring bonds (Silverstein \& Welbster, 1996; Do Carmo, Paim, Dias Filho, \& Stradiotto, 2007).

A decrease of the band at around $700 \mathrm{~cm}^{-1}$ was also observed, related to the $\mathrm{C}-\mathrm{Cl}$ vibrations of $\mathrm{S}$, thus evidencing its partial functionalization and suggesting that not all peripheral groups reacted with the imidazole ligand.

Additionally, the Figures $2(\mathrm{~B})$ and $(\mathrm{C})$, the band is related to the stretching of the $\mathrm{C}=\mathrm{S}$ group $(\mathrm{vC}=\mathrm{S})$ around 768 $\mathrm{cm}^{-1}$ (Prado, Sales, Carvalho, Rubim, \& Airoldi, 2004). The spectra of the compounds in which the $\mathrm{C}=\mathrm{S}$ group is attached to a nitrogen atom (Figure 2(B)) showed an absorption band in the region of axial deformation usual $\mathrm{C}=\mathrm{S}_{(\delta \mathrm{C}=0)}$, and many others in the region between 1563 and $700 \mathrm{~cm}^{-1}$ are assigned to the axial deformation of the $\mathrm{C}=\mathrm{S}_{(\delta \mathrm{C}=0)}$, and $\mathrm{CN}_{(\delta \mathrm{C}-\mathrm{N})}$ respectively (Evangelista, Oliveira, Castro, Zara, \& Prado, 2007), but after functionalization axial deformation $(\delta \mathrm{S}-\mathrm{H})$ disappears and $(\delta \mathrm{C}=\mathrm{O})$ decreases in intensity and undergoes a slight shift to lower frequency region (Figure $2(\mathrm{C})$ ), suggesting that the binding of the aliphatic chain silsesquioxane was carried out via $\mathrm{HS}=\mathrm{C}$ and/or $\mathrm{C}=\mathrm{NH}$ binding. The existence of some absorptions present in $\mathrm{S}$, obscure those present in the binder, damaging a better allocation of absorptions found in SDIT.

According to Figure 2(C) is not observed S-H axial deformation $(\delta \mathrm{S}-\mathrm{H})$ near $2579 \mathrm{~cm}^{-1}$ (Murti, Agnihotri, \& Pathak, 2011). The justification for this is that the cyclic groups $-\mathrm{N}=\mathrm{C}(\mathrm{SH})$ exist in the thiol form $\mathrm{N}=\mathrm{C}(\mathrm{SH})$ and thionine $-\mathrm{NH}-\mathrm{C}(=\mathrm{S})$. These tautomeric forms differ in the location of the corresponding pair is $\mathrm{H}$; thus the absence of a peak S-H may result from the presence of only one tautomeric thiol form. 

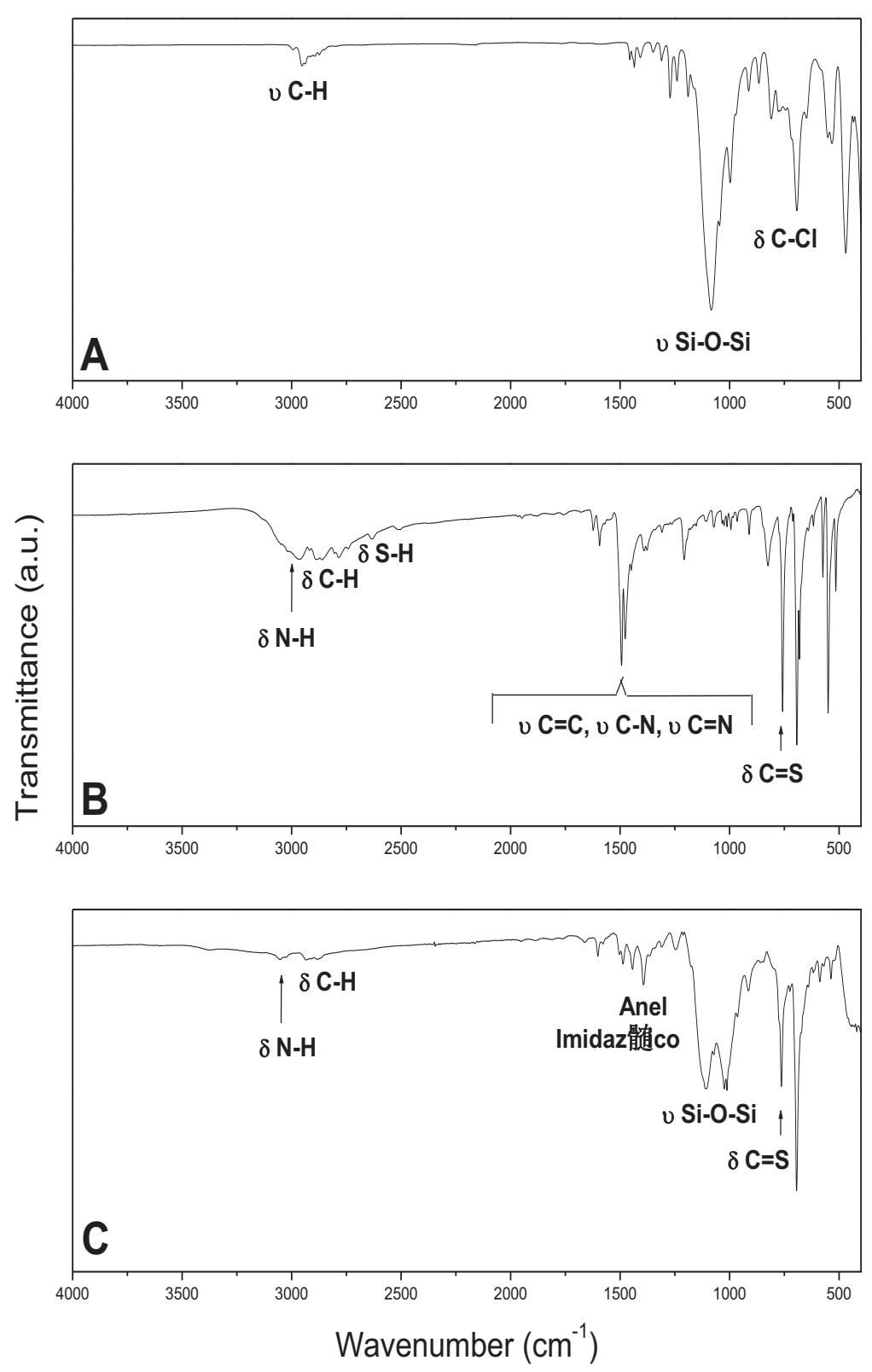

Figure 2. Vibrational spectrum of: (A) S, (B) DIT e, (C) SDIT

Figures 3 and 4 show the spectra of ${ }^{29} \mathrm{Si}$ and ${ }^{13} \mathrm{C}$ NMR of octa(3-chloropropyl)octasilsesquioxane $\left[\mathrm{Cl}\left(\mathrm{CH}_{2}\right)_{3}\right]_{8} \mathrm{Si}_{8} \mathrm{O}_{12}(\mathrm{~S})$, respectively. The spectrum of ${ }^{29} \mathrm{Si}$ NMR (Figure 3) of $\left[\mathrm{Cl}\left(\mathrm{CH}_{2}\right)_{3}\right]_{8} \mathrm{Si}_{8} \mathrm{O}_{12}$ exhibited only a resonance at $-67.42 \mathrm{ppm}$.

As ilustrated by Figure 4 , the ${ }^{13} \mathrm{C}$ NMR spectrum showed three resonances peaks attributed to the three carbons of the propyl groups $(\alpha-10,57, \beta-27,82$ and $\gamma-48,02 \mathrm{ppm})$. These carbons are determined as follows: $\alpha \mathrm{CH}_{2}{ }_{-} \mathrm{CH}_{2} \mathrm{Si}$, $\beta \quad \mathrm{CH}_{2} \mathrm{CH}_{2} \mathrm{CH}_{2}$ and $\gamma \quad \mathrm{Cl}_{2} \mathrm{CH}_{2} \mathrm{CH}_{2}$. These results clearly show the successful synthesis of octa-(3-chloropropyl)octasilsesquioxane (Changyou \& Chunye 2000; Dutkiewicz, Marciejewski, \& Marciniec, 2009; Marciniec, Dutkiewicz, Marciejewski, \& Kubicki, 2008). These results are in agreement with those found in the literature (Marciniec, Dutkiewicz, Marciejewski, \& Kubicki, 2008) thus confirming the successful preparation of the precursor, so the product is pure and able to subsequent reactions. 


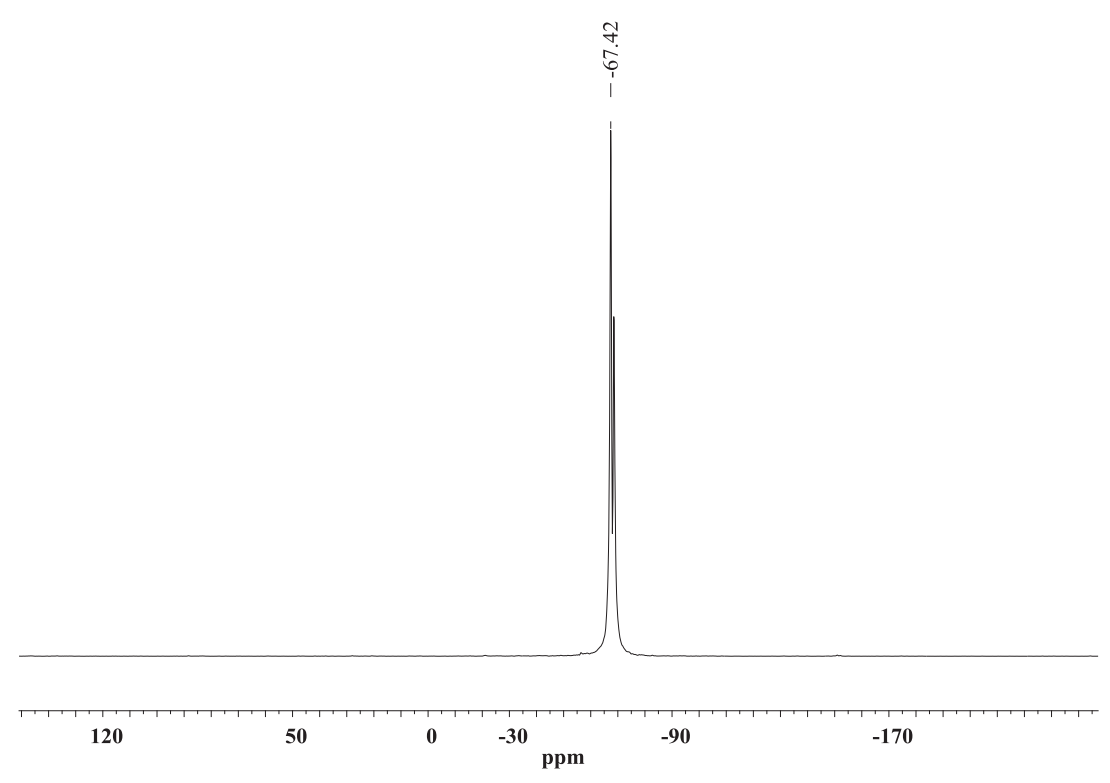

Figure $3 .{ }^{29} \mathrm{Si} \mathrm{NMR}$ of $\mathrm{S}$

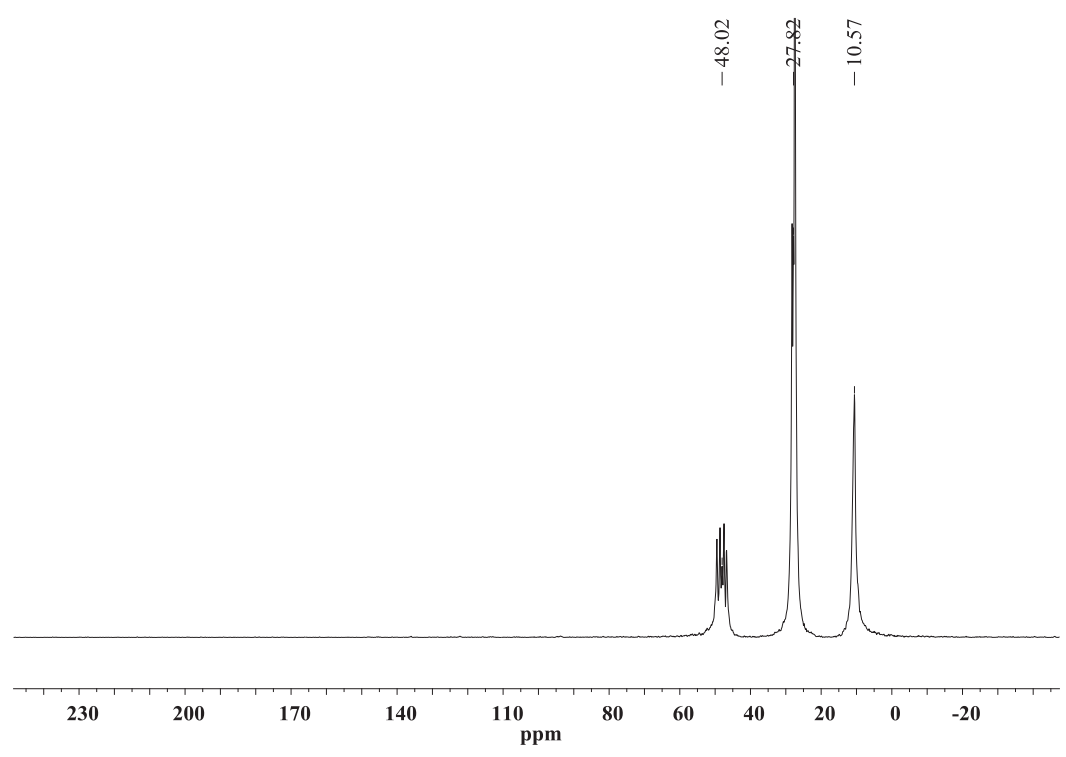

Figure $4 .{ }^{13} \mathrm{C}$ NMR of $\mathrm{S}$

Figure 5 shows the ${ }^{13} \mathrm{C}$ NMR spectrum of the solid SDIT. Eight peaks were observed. The resonances at 10.70, 26.08 and $64.11 \mathrm{ppm}$ corresponding to carbons $\left(\left(\mathrm{CH}_{2} \mathrm{Si}\right) ;\left(\mathrm{CCH}_{2} \mathrm{C}\right) ;\left(\mathrm{NCH}_{2}\right)\right)$ and the composite resonance peak at $47.10 \mathrm{ppm}$ was assigned to the cabono $\gamma$ of octa-(3-chloropropyl)octasilsesquioxano that did not react with the ligand, so it is clear that not all groups of peripheral octa-(3-chloropropyl) octasilsesquioxano been chemically modified. There was a hight intensity resonance at a lower frequency at $128.6 \mathrm{ppm}$ corresponding to carbons of the benzene ring ( 8 carbons) and the carbons bonded to the benzene ring ( 2 carbons). It was also found another peak at $139.25 \mathrm{ppm}$ that was assigned to the imidazole thiol ring NCC. The absence of a resonance peak at $148.89 \mathrm{ppm}$ (HNCS) in the composite, suggesting that the bindind was conducted through the NH group present in the ligand molecule. When this occurs a new peak appears, as described above $\left(\mathrm{NCH}_{2}\right)$. These values are similar to those described in the literature (Prado, Sales, Carvalho, Rubim, \& Airoldi, 2004; Alcântara et al., 2007) for analogous compounds supported on silica -based materials. For comparison purpose, Figure 6 shows the ${ }^{13} \mathrm{C}$ solid state NMR of DIT, where exactly were observed 4 resonance peaks. The carbons peak resonances at 128.89 at $148.89 \mathrm{ppm}$ were assigned to 8 carbons and the benzene ring (attached) and to 2 carbon imidazol thiol rings. The peak at 157.64 was assigned to carbon HNCS. 


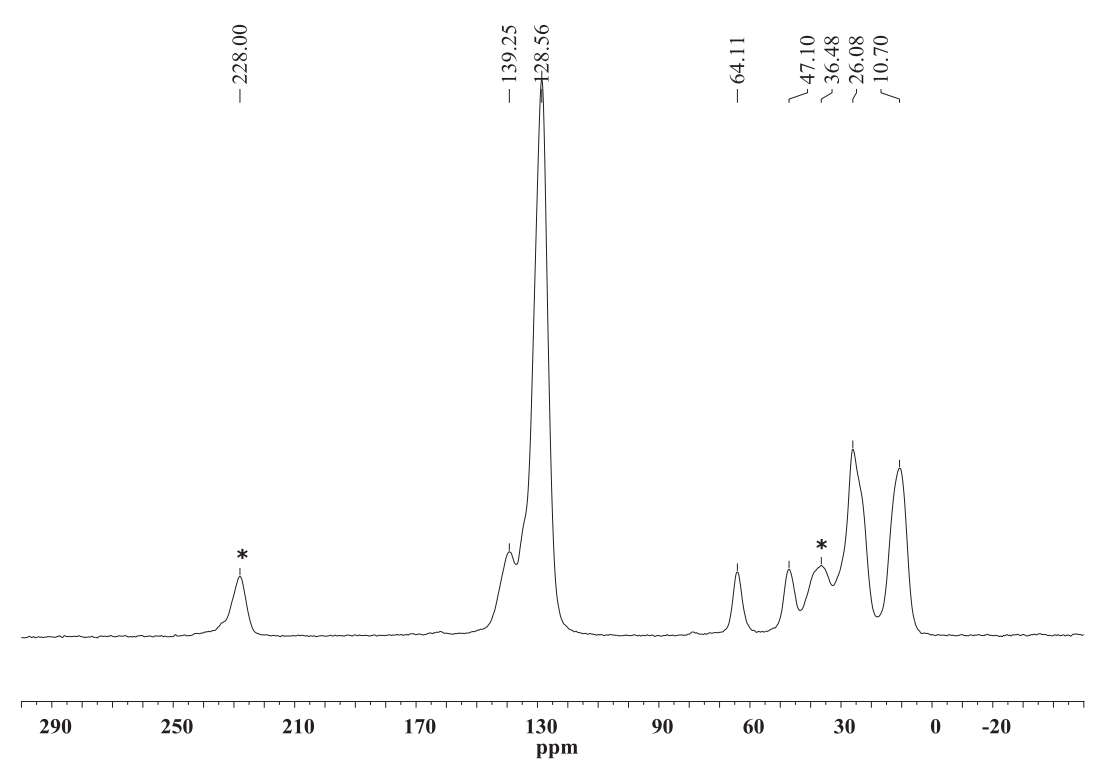

Figure $5 .{ }^{13} \mathrm{C}$ NMR of SDIT. * Side bands

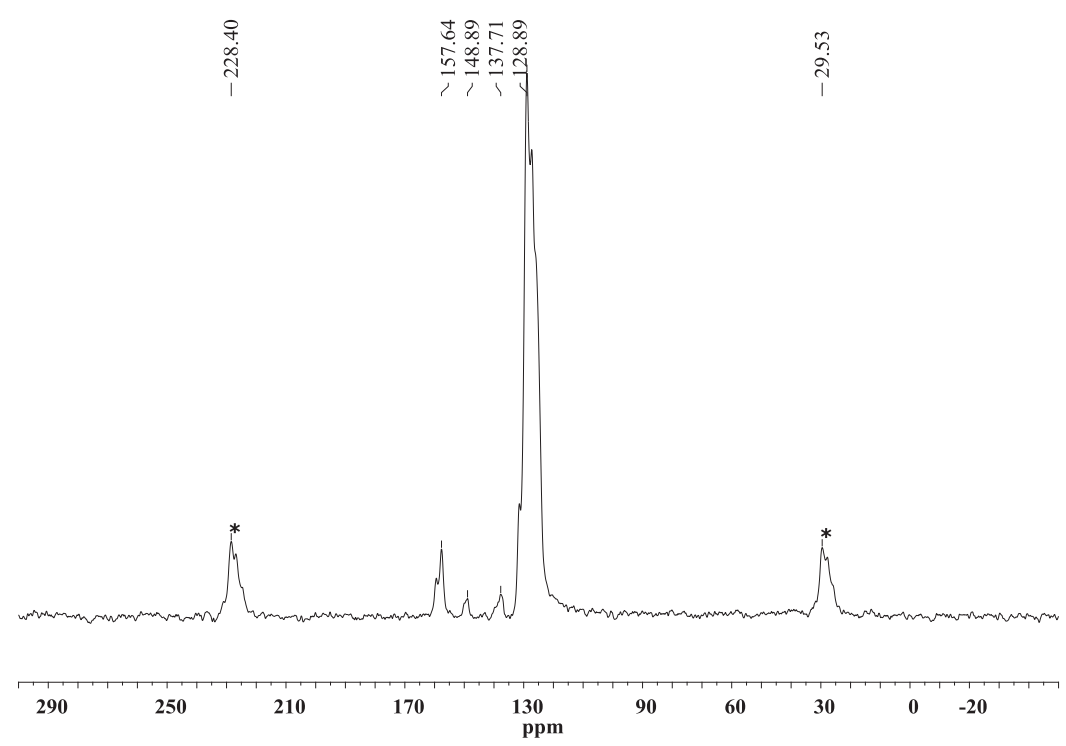

Figure 6. NMR ${ }^{13} \mathrm{C}$ of DIT. *Side bands

Figure 7 shows the ${ }^{29} \mathrm{Si}$ NMR spectrum in solid state of SDIT. During the functionalization of octa-(3-chloropropyl)octasilsesquioxano with DIT new covalent Si-O-Si bonds are formed by $\mathrm{T}^{3}$ structural units (Harrison, 1997; Urich, Cannizzaro, Langer, \& Shakesheff, 1999), which corresponds to an intense and broad peak at $-68.93 \mathrm{ppm}$, confirming the cubic structure containing silicon.

Figures $8(\mathrm{~A})$, (B) and (C) corresponds to the XRD patterns of S, DIT and SDIT respectively. According to the XRD patterns obtained, a crystallinity quite common for octa-(3-chloropropyl)octasilsesquioxanes cubic (A) was obeserved (Bard \& Faulkner, 2001). The S (A) showed the following characteristics $2 \theta=7.36,9.19,10.43,10.93$, $12,13.33,14.22,19.12,19.54,20.55,21.95,22.95,24.04,26.48,26.74,27.5,28.4,29.4,30.5$. The DIT (B) crystalline, had the characteristics $2 \theta=8.53,10.23,12.01,14.53,15.25,15.97,16.81,17.53,19.09 ; 20.63,22.83$, $23.91,25.83,27.54,28.03,28.87,30.43,39.22$. It was observed that after the organofunctionalization SDIT (C) showed no crystallinity their precursors (S and DIT) XRD. It was observed only two peaks $((2 \theta), 11.05$ and 
20.51). This behavior is typical analogs compounds and indicated a substantial loss of crystallinity possibly due to a formed polymer network (Do Carmo, Paim, Dias Filho, \& Stradiotto, 2007).

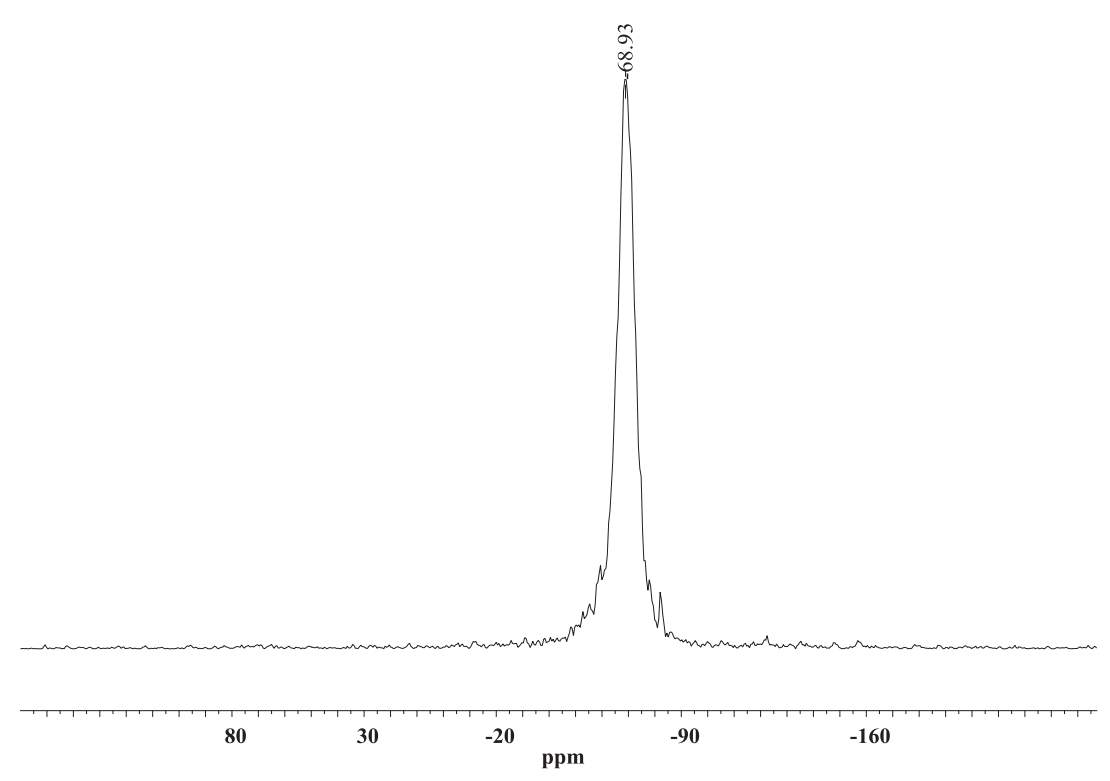

Figure 7. Espectro de RMN ${ }^{29}$ Si no estado sólido do SDIT
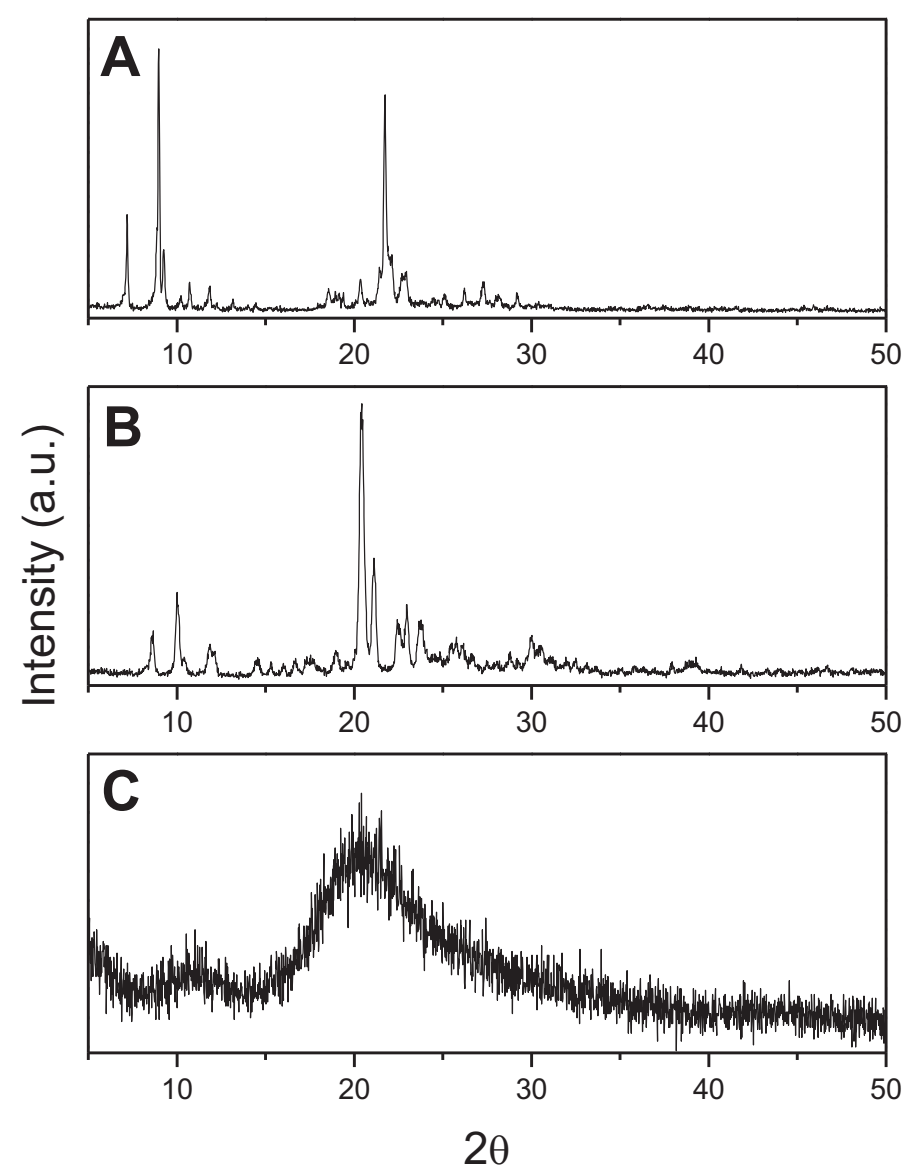

Figure 8. XRD of: (A) S, (B) DIT e, (C) SDIT 
Figures 9(A), (B) and (C) show the scanning electron microscopy (SEM) of the octa-(3-chloropropyl)octasilsesquioxano (S), the DIT and SDIT with an increase of $10.000 \mathrm{X}$, respectively. Through the micrographs was possible to note the presence of cubic structural shapes with an average size of about 9 microns although they also can be observed cubic structures having size of $454 \mathrm{~nm}$ (Figure 9(A)). The scanning electron microscopy of 4,5-Diphenyl-2-imidazolethiol (DIT) is illustrated in Figure 9(B). It was observed the presence of dispersed microparticles with sizes of 8.5 to 10.0 micrometers. Figure $9(\mathrm{C})$ shows the micrograph of the $\mathrm{S}$ after their functionalization with groups 4-5-diphenyl-2-imidazoltiol (SDIT), where you can view a cluster of particles containing cavities in an orderly fashion.

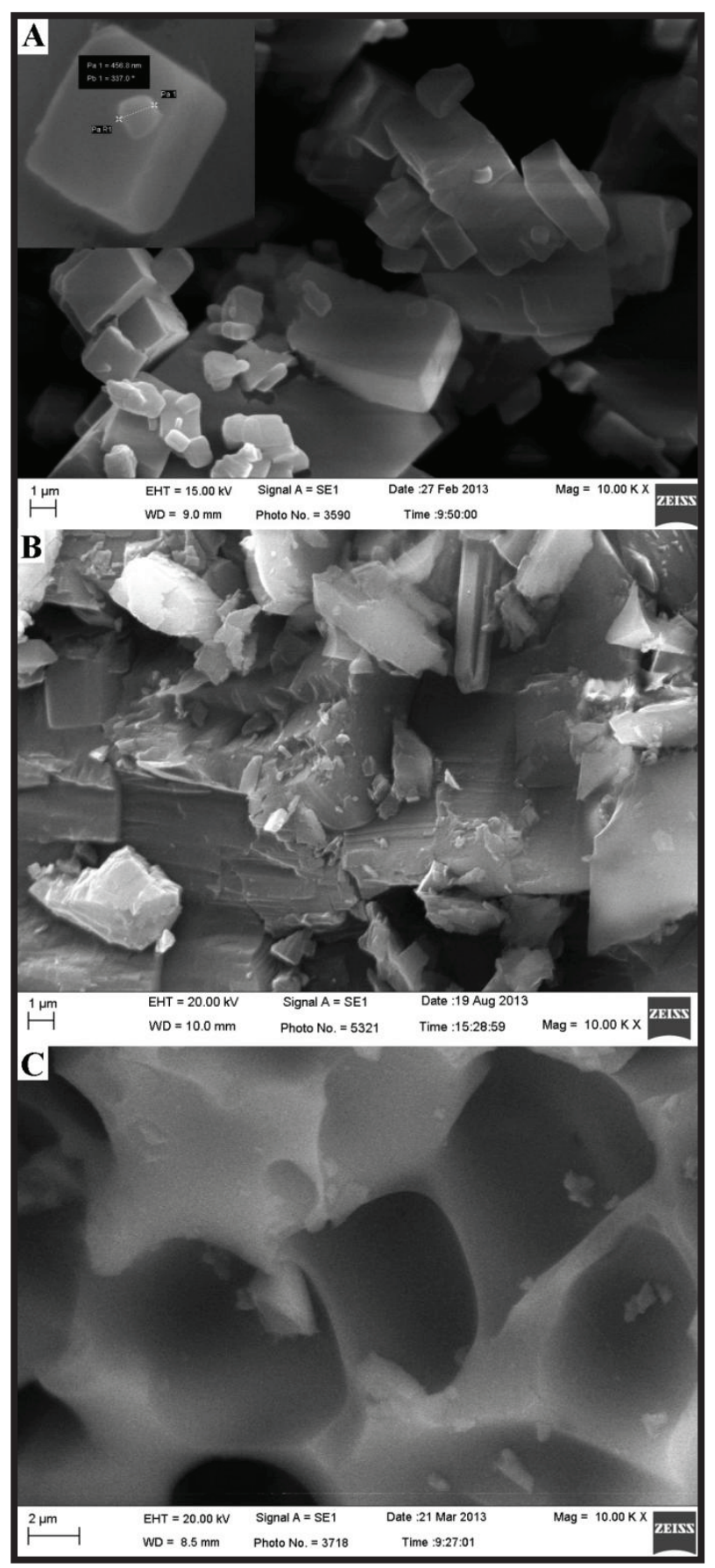

Figure 9. SEM of: (A) S, (B) DIT e, (C) SDIT 
Figure 10(A), (B) and (C) show energy dispersive spectroscopy analyses (EDS) for S, DIT and SDIT samples respectively. It was observed in the EDS spectrum of $\mathrm{S}(\mathrm{A})$ the presence of $\mathrm{Si}, \mathrm{O}, \mathrm{C}$ and $\mathrm{Cl}$ present in octa-(3-chloropropyl)octasilsesquioxane cubic. In the EDS spectrum for 4,5-diphenyl-2-imidazoltiol (DIT) (B) revealed the presence of $\mathrm{C}, \mathrm{N}$ and S. For organofunctionalizade materials (SDIT) (C) revealed a small $\mathrm{Cl}$ presence and a high concentration of S, which clearly shows the success in the preparation of SDIT.

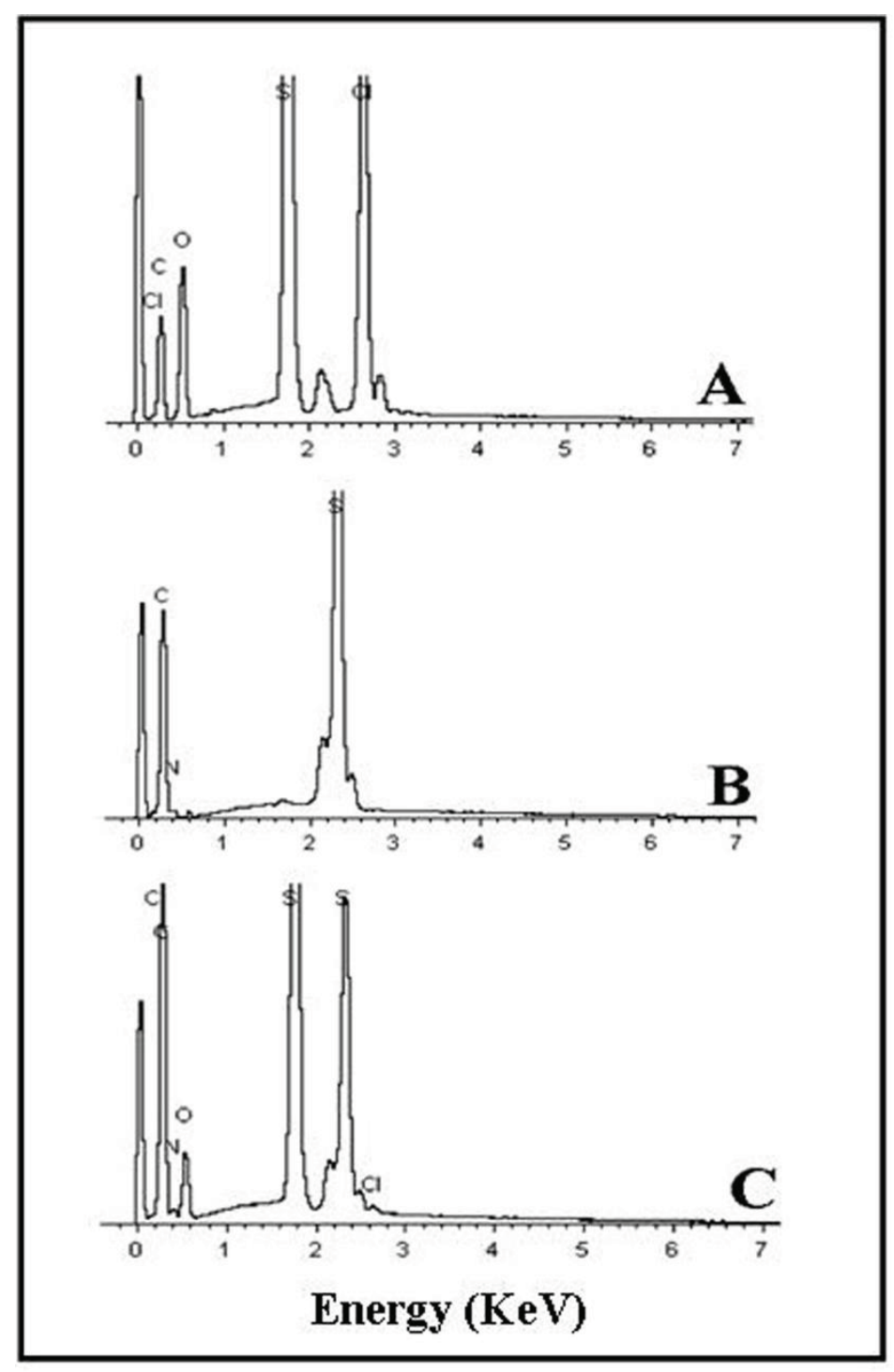

Figure 10. EDS of: (A) S, (B) DIT e, (C) SDIT

The thermogravimetric curves indicate the thermal stability of materials forward to heating with continuous and programmed temperature (Hatakeyama \& Quinn, 1999) rate.

As shown in Figure 11(A) the thermogram of octa-(3-chloropropyl)octasilsesquioxano (S) in a nitrogen atmosphere, showed two stages of weight loss. In the first stage the weight loss $\left(68 \%\right.$ occurred from 350 to $450{ }^{\circ} \mathrm{C}$ mass loss was (68\%) attributed to oxidation of organic matter (Zhang, Liang, \& Lu, 2007).

It was observed that the material had a certain thermal stability up to $400{ }^{\circ} \mathrm{C}$ and in the second stage the weight loss occurred from 450 to $650{ }^{\circ} \mathrm{C}(7 \%)$ attributed to the decomposition of residual groups $\mathrm{SiCH}_{3}$ (Hatakeyama \& Quinn, 1999) present in the sample. The residue was $25 \%$, and assigned to the same carbonaceous. Figures 11(B) and (C) illustrate the thermograms in nitrogen atmosphere of 4,5-diphenyl-2-imidazoltiol (DIT) and functionalized materials (SDIT), respectively. In the thermogram of DIT was observed two stages of weight loss, for the first 275 
to $400{ }^{\circ} \mathrm{C}(55 \%)$ attributed to loss of organic matter in the sample and the other occurring degradation stage was from 400 to $700{ }^{\circ} \mathrm{C}(45 \%)$, which can also be attributed to degradation of organic matter in the sample. The thermogram of SDIT also presented two stages of mass loss, one of 310 to $450{ }^{\circ} \mathrm{C}(40 \%)$, and the second event was observed from 450 to $700{ }^{\circ} \mathrm{C}(23 \%)$ both attributed to degradation of organic matter present in the sample, residue was $37 \%$, being attributed to carbonaceous. Additionally, it was observed that the $\mathrm{S}$ and DIT materials in nitrogen atmosphere showed some thermal stability up to temperatures around $250{ }^{\circ} \mathrm{C}$.

The thermogravimetric curves in an air atmosphere of octa-(3-chloropropyl)octasilsesquioxano (S) of 4,5diphenyl-2- imidazoltiol (DIT) and octa-(3-chloropropyl)octasilsesquioxano functionalized (SDIT), are illustrated through Figure 11(D, E and F), respectively. The thermogram showed a stage $\mathrm{S}$ of weight loss from 220 to $700{ }^{\circ} \mathrm{C}$ (57\%) attributed to degradation of the organic part present in the sample. The residue (43\%) was silicon oxide. Figure 11(E) shows the thermogravimetric analysis of the DIT, there was two weight loss stages, the first of 250 to $350{ }^{\circ} \mathrm{C}(50 \%)$ and the second stage from 350 to $700{ }^{\circ} \mathrm{C}(50 \%)$ all of which are related to the oxidation organic part of the sample, there was no leftover residue, because all the material has degraded. In the thermogram SDIT illustrated in Figure 11(A), there are two stages of weight loss, both assigned to degradation and oxidation of organic matter present in the sample, and the first stage was from 320 to $450{ }^{\circ} \mathrm{C}(46 \%)$ and it was observed that the second stage occurred at the temperature range of 450 to $700{ }^{\circ} \mathrm{C}(30 \%)$. The residue was $24 \%$, and assigned to silicon oxide. It was possible to compare the thermogravimetric analyzes performed in two different atmospheres, concluding that the materials (S, DIT and SDIT) when in air atmosphere has a slower degradation process in relation to nitrogen atmosphere. It was also observed that the SDIT possesses greater thermal stability in nitrogen.
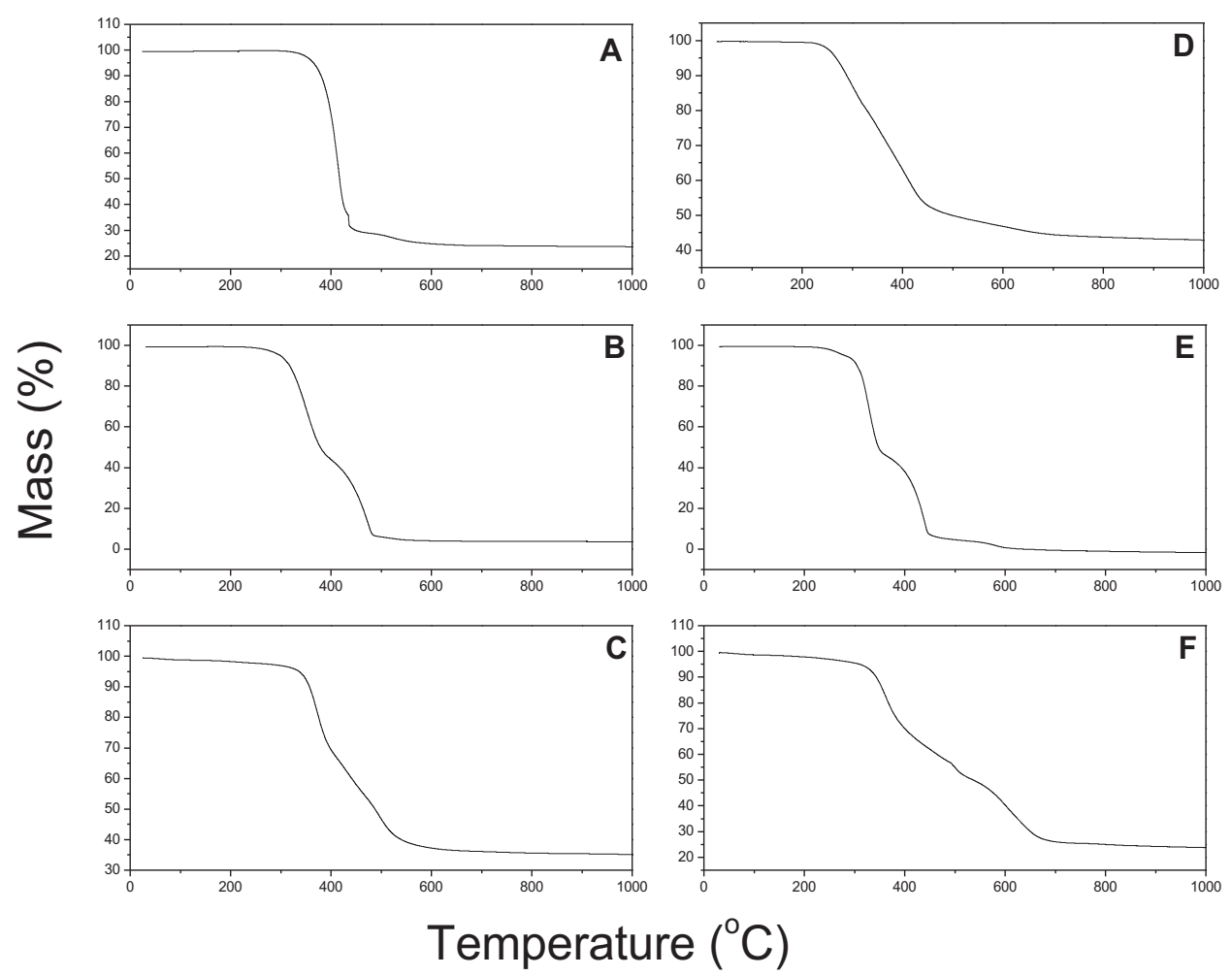

Figure 11. Thermogravimetric curves of: (A) S; (B) DIT; (C) SDIT (Nitrogen atmosphere); (D) S; (E) DIT; (F) SDIT (air atmosphere)

\section{Conclusion}

The organofunctionalization of octa-(3-chloropropyl)silsesquioxane with DIT (SDIT) was perfomated with relative success. The spectroscopic analysis (NMR, EDS and SEM) reveals that not all groups of peripheral octa-(3-chloropropyl)octasilsesquioxane been chemically modified and a loss of crystallinity after organofunctionalization. The SDIT possesses greater thermal stability in nitrogen up $250{ }^{\circ} \mathrm{C}$. 


\section{Acknowledgements}

The financial support for this research was supplied by Fundação de Amparo à Pesquisa do Estado de São Paulo (FAPESP - Processes: 2012/05438-1, 2003/12882-6 and 2012/11306-0); Conselho Nacional de Desenvolvimento Científico e Tecnológico (CNPq) Processe. 306087/2012-0. The authors are thankful to Prof. Dr. Massao Ionashiro for performing the thermal analysis and Prof. Dr. Eudes Borges de Araújo for the X-Ray diffraction analysis.

\section{References}

Alcântara, E. F. C., Faria, E. A., Rodrigues, D. V., Evangelista, S. M., Oliveira, E., Zara, L. F., ... Prado, A. G. S. (2007). Modification of sílica gel by attachment of 2-mercaptobenzimidazole for use in removing $\mathrm{Hg}$ (II) from aqueous media: A thermodynamic approach. Journal Colloid and Interface Science, 311, 1-7. http://dx.doi.org/10.1016/j.jcis.2007.02.075

Baney, R. H., Itoh, M., Sakakibara, A., \& Suzukit, T. (1995). Silsesquioxanes. Chemical Reviews, 95, $1409-1430$. http://dx.doi.org/10.1021/cr00037a012

Bard, A. J., \& Faulkner, L. R. (2001). Electrochemical methods: Fundamentals and applications (2nd ed.). New York, NY: John Wiley \& Sons.

Barth, A. (2000). The infrared absorption of amino acid side chains: Review. Progress in Biophysics \& Molecular Biology, 74, 141-173. http://dx.doi.org/10.1016/S0079-6107(00)00021-3

Coates, J. (2000). Interpretation of Infrared Spectra, A Practical Approach. Chichester: John Wiley \& Sons LTD.

Cordes, D. B., Lickiss, P. D., \& Rataboul, F. (2010). Recent developments in the chemistry of cubic polyhedral oligosilsesquioxanes. Chemical Reviews, 110, 2081-2173. http://dx.doi.org/10.1021/cr900201r

Do Carmo, D. R., Bicalho, U. O., Silveira, T. F., Dias Filho, N. L., \& Paim, L. L. (2013). Determination of Copper in Different Ethanolic Matrices Using a Chloropropyl Silica Gel Modified with a Nanostructured Cubic Octa(3-aminopropyl)octasilsesquioxane. Journal of Chemistry, 2013, 1-11. http://dx.doi.org/10.1155/2013/509341

Do Carmo, D. R., Paim, L. L., Dias Filho, N. L., \& Stradiotto, N. R. (2007). Preparation, characterization and application of a nanostructured composite: Octackis (cyanopropyldimetylsiloxy) octasilsesquioxane. Applied Surface Science, 253, 3683-3689. http://dx.doi.org/10.1016/j.apsusc.2006.07.080

Dutkiewicz, M., Maciejewski, H., \& Marciniec, B. (2009). Functionalization of Polyhedral Oligomeric Silsesquioxane (POSS) via Nucleophilic Substitution. Journal of Synthetic Organic Chemistry, 12, 2019-2024. http://dx.doi.org/10.1055/s-0029-1216807

Evangelista, S. M., Oliveira, E., Castro, G. R., Zara, L. F., \& Prado, A. G. S. (2007). Hexagonal mesoporous silica modified with 2-mercaptothiazoline for removing mercury from water solution. Surface Science, 601, 2194-2202. http://dx.doi.org/10.1016/j.susc.2007.03.020

Harrison, P. G. J. (1997). Silicate cages: precursors to new materials. Journal of Organometallic Chemistry, 542, 141-183. http://dx.doi.org/10.1016/S0022-328X(96)06821-0

Hatakeyama, T., \& Quinn, F. X. (1999). Thermal analysis: Fundamentals and applications to polymer Science (1st ed.). Aulnay-sous-Bois: Wiley.

Kuo, S. W., \& Chang, F. C. (2011). POSS related polymer nanocomposites. Progress in Polymer Science, 36, 1649-1695. http://dx.doi.org/10.1016/j.progpolymsci.2011.05.002

Laine, R. M., \& Roll, M. (2011). Polyhedral Phenylsilsesquioxanes. Macromolecules, 44, $1073-1109$. http://dx.doi.org/10.1021/ma102360t

Li-Chih, H., \& Shea, K. J. (2011). Organo-silica hybrid functional nanomaterials: how do organic bridging groups and silsesquioxane moieties work hand-in-hand? Chemical Society Reviews, 40, 688-695. http://dx.doi.org/10.1039/c0cs00219d

Marciniec, B., Dutkiewicz, M, Marciejewski, H., \& Kubicki, M. (2008). New, Effective Method of Synthesis and Structural Characterisation of Octakis(3-chloropropyl)octasilsesquioxane. Organomettalics, 27, 793-794. http://dx.doi.org/10.1021/om700962x

Murti, Y., Agnihotri, R., \& Pathak, D. (2011). Synthesis, Characterization and Pharmacological Screening of Some Substituted 1,2,3- \& 1,2,4-Triazoles. American Journal of Chemistry, 1, 42-46. http://dx.doi.org/10.5923/j.chemistry.20110102.09 
Phillips, S. H., Haddad, T. S., \& Tomezak, S. J. (2004). Developments in nanoscience: polyhedral oligomeric silsesquioxane (POSS)-polymers. Current Opinion in Solid State-Materials Science, 8, 21-29. http://dx.doi.org/10.1016/j.cossms.2004.03.002

Prado, A. G. S., Sales, J. A. A., Carvalho, R. M., Rubim, R. J., \& Airoldi, C. J. (2004). Immobilization of 5-amino-1,3,4-thiadiazole-thiol onto silica gel surface by heterogeneous and homogeneous routes. Non-Cryst. Solids, 333, 61-67. http://dx.doi.org/10.1016/j.jnoncrysol.2003.09.053

Silverstein, R. M., \& Welbster, F. X. (1996). Spectrometric identification of organic compounds (7th ed.). New York, NY: John Wiley and Sons.

Soares, L. A., Silveira, T. F. S., Silvestrini, D. R., Bicalho, U. O., \& Do Carmo, D. R. (2013). Use of a silsesquioxane organically modified with 4-amino-5-(4-pyridyl)-4H-1,2,4-triazole-3-thiol (APTT) for adsorption of metal ions. International Journal of Chemistry, 5, 39-48. http://dx.doi.org/10.5539/ijc.v5n1p39

Tanaka, K., \& Chujo, Y. (2012). Advanced Luminescent Materials Based on Organoboron Polymers. Macromolecular Rapid Communications, 33, 1235-1255. http://dx.doi.org/10.1002/marc.201200239

Urich, K. E., Cannizzaro, S. M., Langer, R. S., \& Shakesheff, K. M. (1999). Polymeric Systems for Controlled Drug Release. Chemical Reviews, 99, 3181-3198. http://dx.doi.org/10.1021/cr940351u

Xu, D., Loo, L. S., \& Wang, K. (2011). Characterization and diffusion behavior of chitosan-poss composite membranes. Journal of Applied Polymer Science, 122, 427-435. http://dx.doi.org/10.1002/app.34146

Zhang, Z., Liang, G., \& Lu, T. (2007). Synthesis and Characterization of Cage Octa (aminopropylsilsesquioxane). Journal of Applied Polymer Science, 103, 2608-2614. http://dx.doi.org/10.1002/app.25304

\section{Copyrights}

Copyright for this article is retained by the author(s), with first publication rights granted to the journal.

This is an open-access article distributed under the terms and conditions of the Creative Commons Attribution license (http://creativecommons.org/licenses/by/3.0/). 